\title{
Evaluation of children with protein energy malnutrition and level of malaria parasitemia in Kwara State, Nigeria
}

\author{
Aishat Oluwatoyin Saka, ${ }^{1}$ Mohammed Jamiu Saka, ${ }^{2}$ Lateefat Olayinka Sa'adu ${ }^{3}$ \\ ${ }^{1}$ Department of Pediatric and Child Health, and ${ }^{2}$ Department of Epidemiology and Community Health, \\ Faculty of Clinical Sciences, College of Health Sciences, University of Ilorin, Kwara State; \\ ${ }^{3}$ Department of Medical Microbiology and Parasitology, University of Ilorin Teaching Hospital, Ilorin, \\ Kwara State, Nigeria
}

\begin{abstract}
Malaria and Protein-Energy-Malnutrition (PEM) are two major causes of childhood mortality in sub-Saharan Africa. Malaria can predispose a child to PEM and the reverse may also be true. Recent studies have presented inconsistent findings about nutritional status and the occurrence of malaria among the children. The goal of this study was to evaluate the association between PEM and malaria parasitemia if any. A case control study in which 90 children diagnosed for PEM (aged 6-59 months), and another well-nourished 90 children age and sex-matched controls were evaluated for malaria parasitemia. A semi-structured proforma was used to obtain relevant information on the children's socio-
\end{abstract}

Correspondence: Lateefat Olayinka Sa'adu, Department of Medical Microbiology and Parasitology, University of Ilorin Teaching Hospital, Ilorin, Kwara State, Nigeria.

Tel: +234.8038134711 .

E-mail: lateemayaki88@yahoo.com

Key words: PEM, malaria parasitemia.

Acknowledgments: we are highly grateful to the authors who have contributed to the funding, writing and review of this manuscript for publication. We are also grateful to the University of Ilorin Teaching hospital where the research work was carried out. We are also grateful to Mr. Olatunbosun of the Haematology department of the same hospital, who assisted in blood sample analysis.

Contributions: AOS, manuscript writing and reference search; MJS, manuscript reviewing; LOS, data collecting and analyzing.

Conflict of interest: the authors declare no potential conflict of interest.

Funding: none.

Received for publication: 12 July 2018.

Revision received:20 August 2018.

Accepted for publication: 27 October 2018.

This work is licensed under a Creative Commons Attribution NonCommercial 4.0 License (CC BY-NC 4.0).

(C) Copyright A.O. Saka et al., 2018

Licensee PAGEPress, Italy

Annals of African Medical Research 2018; 1:33

doi:10.4081/aamr.2018.33 demographic characteristics, nutritional indices amongst others. Venous blood sample was collected and thick and thin blood film were prepared and viewed under the microscope. Malaria parasitemia was present in $82(91.1 \%)$ of malnourished group and 12 $(13.3 \%)$ of the well-nourished group $(\mathrm{P}<0.05 \mathrm{OR}=66.62)$. Malaria parasitemia was highest in those with kwashiorkor and marasmic kwashiorkor compared with underweight. These differences were statistically significant $(\mathrm{P}<0.05)$. The study demonstrates that malnourished children have higher degree of malaria parasitemia and are at risk of malaria. It also shows that severe forms of malnutrition are associated with heavier malaria parasitemia. It is therefore recommended that all malnourished children should have access to use of Insecticide Treated Nets (ITN), malaria chemoprophylaxis as well as empiric treatment of malaria in endemic areas where access to malaria parasite diagnosis is difficult.

\section{Introduction}

Protein energy malnutrition (PEM) is a leading cause of morbidity and mortality among children less than fivers of age worldwide, especially in the developing countries. ${ }^{1}$ Causes of severe morbidities as well as mortality usually result from complications associated with the condition as well as the existence of other comorbidities. The presence of Infection is a common cause of death among children with protein energy malnutrition. Common causes of infection in them include bacteria, viral and parasitic infections. A common parasitic infection which can occur as co-morbidity is Malaria. ${ }^{1}$

Malaria and under-nutrition are the two major causes of childhood mortality in sub-Saharan Africa. ${ }^{2}$ Complex relationships exist between malaria and malnutrition. Complicated malaria can predispose a child to malnutrition while a malnourished child can be predisposed to be infected with malaria. ${ }^{2,3}$ Malaria like PEM is commonly associated with poverty; both can also be a cause of poverty and are major hindrance to economic development. ${ }^{1}$ Both have common effects such as chronic anemia, impaired growth, and delayed cognitive development on children., ${ }^{1,2}$

The impact of malnutrition on malaria outcome as well as that of malaria on nutritional outcome has been studied by previous authors. $^{2-9}$ A number of observations have indicated a deleterious effect of malaria on nutritional status, ${ }^{2,3}$ as children studied then who had at least one episode of malaria during this period presented lower mean anthropometric index scores compared to children who did not have malaria. ${ }^{3}$ However, some earlier observational studies did provide some evidence of protective effect of undernutrition against malaria as children with malnutrition had asymptomatic malaria. ${ }^{4-6}$ Some other studies ${ }^{7,8}$ have found no synergist relationship between malaria and malnutrition. This could be 
attributed to the nature of the study population utilized which were HIV infected and non-infected children who had control measures for both malaria and malnutrition instituted routinely. These confounders might be responsible for such observation. ${ }^{7,8}$ The outcome of malaria on the nutritional status of malaria parasitemia in children with protein energy malnutrition has also been clearly defined by studying the anthropometry as well as other parameters through acute case management as well follow up of affected cases over time. ${ }^{3}$ These previous studies were carried out basically assessing the nutritional status of children with malaria. However, the effect of nutritional status on host resistance to acquisition and progression of malaria is still not clearly defined. A clear relationship has to be defined between these very important causes of childhood morbidity and mortality in this part of the world. Thus, the goal of this study was to evaluate whether malnutrition is associated with increased or decreased malaria parasitemia in children with malnutrition compared with age matched well-nourished children.

\section{Materials and Methods}

This was a case control study in which subjects were children diagnosed with PEM with ages between 6 and 59 months and controls were children with normal nutritional status admitted to pediatric ward of the University of Ilorin Teaching hospital which is located in the North Central zone of Nigeria. PEM patient were classified based on the Wellcome classification. ${ }^{10}$

Clinical examination and anthropometric measurements such as weight and height were carried out among the subjects by the investigator. The weight was measured to the nearest 0.1 kilogram using standardized scales while the length was measured to an accuracy of 0.1 meter using an infantometer for children less than 2 years and a stadiometer for height among children older than 2 years.

A semi-structured questionnaire was used to obtain information from the subjects using an interview method. Relevant information on the children's socio-demographic characteristics, nutritional indices and laboratory findings were documented.

Socio-economic index scores were awarded to the occupations and educational attainments of their parents or caregivers using the Oyedeji socio-economic classification scheme. ${ }^{11}$ Socio economic class I and II are the upper socio-economic class, class III is the middle class while socio economic class IV and V are the lower socio-economic class. ${ }^{11}$

The study was approved by the Ethics and Research
Committee of the University of Ilorin Teaching Hospital. Informed consent was sought from the parents.

\section{Sample collection and analysis}

Under strict aseptic conditions, after cleaning the blood collection site thoroughly with $70 \%$ alcohol, 1 mili liter of venous blood was collected by venepuncture using a fixed hypodermic needle. Blood films were prepared both thin and thick films in the standard manner. ${ }^{12}$ The slide was then air dried and the films were then fixed with methanol or ethanol on a standing rack. After about three minutes, staining was done with $10 \%$ Giemsa stain diluted to $\mathrm{pH}$ of 7.2 with phosphate buffer for 10 minutes after which clean water was used to wash the stains.

\section{Reporting the thick film}

The report of the thick film was done using the protocol described by Cheesbrough. ${ }^{12}$ Briefly, a drop of immersion oil was applied to the film and viewed under microscope using the $100 \mathrm{x}$ objective to examine at least 100 high power fields (HPF). The finding was reported as:

1-10 parasites per 100HPF was recorded as +

11-100 parasites per $100 \mathrm{HPF}$ as ++

1-10 parasites in one HPF as +++

More than 10 parasites in one HPF as ++++

Data entry and analysis were carried out with a micro-computer using the Epi info version 3.5 (2008) software packages. P value was set at $<0.05$ for significant relationships. Odd ratio interpretation was $1=$ equal risk in the two group, $<1=$ lesser risk in the first group and $>1=$ higher risk in the first group. The malnourished children form the first group while the controls formed the second group.

\section{Results}

A total of 90 children with PEM and 90 well-nourished children were studied. Of the 90 children with PEM, 59 (65.6\%) were males and $31(34.4 \%)$ were females, (M: F ratio 1.9:1). While of the 90 well-nourished ones, $53(58.9 \%)$ were males and 37 (41.1\%) were females (M: F ratio1.4:1.) $(\mathrm{P}=0.36)$. The mean age of the children with PEM was $22.7+14.4$ months while the mean age of the control was $29.3+16.9$ months $(\mathrm{P}=0.08)$. Children with PEM were mainly from low socio-economic class and there was a statistically significant difference in the social economic status of the malnourished group and the well-nourished group $(\mathrm{P}=0.00001)$ as shown in Table 1 . Fifty (55.6\%) children with PEM were under-

Table 1. The socio-demographic characteristics of the malnourished and controls.

\begin{tabular}{|c|c|c|c|c|}
\hline Variable & PEM $(n=90)$ & Controls $(\mathrm{n}=90)$ & $\chi^{2}$ & $\mathbf{P}$ \\
\hline Age (month), Range & $9.0-59.0$ & $6.0-59.0$ & $\mathrm{t}=7.95$ & 0.08 \\
\hline Mean \pm S.D & $22.7 \pm 14.4$ & $29.3 \pm 16.9$ & & \\
\hline $\begin{array}{l}\text { Gender } \\
\text { Male } \\
\text { Female }\end{array}$ & $\begin{array}{l}59(65.6 \%) \\
31(34.4 \%)\end{array}$ & $\begin{array}{l}53(58.9 \%) \\
37(41.1 \%)\end{array}$ & 0.85 & 0.356 \\
\hline $\begin{array}{l}\text { Social Ecnomic Class } \\
\text { I } \\
\text { II } \\
\text { III } \\
\text { IV } \\
\text { V }\end{array}$ & $\begin{array}{c}2(2.2) \\
6(6.8) \\
26(28.8) \\
38(42.2) \\
18(20.0)\end{array}$ & $\begin{array}{c}4(4.4) \\
27(30.0) \\
35(38.9) \\
16(17.8) \\
8(8.9)\end{array}$ & 28.17 & 0.000012 \\
\hline
\end{tabular}


weight, 21(23.3\%) had marasmus, $11(12.2 \%)$ had marasmickwashiokor and $8(8.8 \%)$ had kwashiorkor (Table 2). Of the malnourished $82(91.1 \%)$ had malaria parasitemia compared with 12 $(13.3 \%)$ of the well-nourished ones. There was a statistically significant difference $(\mathrm{P}=0.0001)$ (Table 3$)$. All the $11(100 \%)$ children with kwashiorkor as well as all the $8(100 \%)$ with marasmickwashiokor were positive for malaria parasitemia. Nineteen (90.5\%) of the 21 children with Marasmus and $44(88.0 \%)$ of underweight children also had malaria parasitemia. Each of these compared with the well-nourished children Malaria Parasitemia in Children with Protein Energy showed statistically significant differences $(\mathrm{P}<0.05)$. The degree of parasitemia in each of the types of PEM is as shown in the Table 4.

\section{Discussion}

Malaria and PEM are common in sub-Saharan Africa, it is therefore important to understand the relationship which exists between them because of its enormous public health importance.

This present study shows that over ninety percent of the malnourished children studied had malaria parasitemia. There was also a significant difference when the density of parasitemia of the malnourished was compared with that of well-nourished children. The

Table 2. Distribution of types of protein energy malnutrition.

\begin{tabular}{lcc} 
Type of PEM & Frequency & Percentage \\
Kwashiorkor & 8 & 8.9 \\
Marasmus & 21 & 32.2 \\
\hline Marasmus-Kwashiorkor & 11 & 12.2 \\
Underweight & 50 & 55.6 \\
\hline Total & 90 & 100 \\
\hline
\end{tabular}

Table 3. Malaria parasitemia among PEM and non-PEM.

\begin{tabular}{lcc} 
Malaria Parasitemia & $\begin{array}{c}\text { Patients with PEM, } \\
\text { n (\%) }\end{array}$ & $\begin{array}{c}\text { None PEM Patients, } \\
\text { n (\%) }\end{array}$ \\
None & $8(8.9)$ & $78(86.7)$ \\
$+(1-10$ Parasite /100HPF) & $63(70)$ & $7(7.8)$ \\
\hline$++(11-100$ Parasite /100HPF) & $18(20)$ & $5(5.0)$ \\
$+++(1-10$ parasites/HPF) & $1(1.1)$ & None \\
\hline Total & $90(100)$ & $90(100)$ \\
\hline
\end{tabular}

odds ratio further strengthens this fact as the findings derived demonstrate a higher risk of malaria among the malnourished children. Our findings show that undernourished children experienced more, not less, malaria parasitemia when compared to well-nourished children. This finding is similar to previous studies. A more recent study in Ibadan Nigeria by Olumese et al. ${ }^{13}$ also reported that malnutrition was associated with severe forms of malaria.

In Sudanese children, el Samani et al. reported that malaria was more often seen in malnourished than in adequately nourished children. ${ }^{14}$ Other studies from Tanzania, ${ }^{15}$ Chad, ${ }^{16}$ Zaire $^{17}$ and Kenya ${ }^{18}$ also confirm the greater risk of malaria among children with poor nutritional status. Another longitudinal study from Vanuatu ${ }^{19}$ supports the claim that malnutrition predisposes the host to malaria infection. However, none of these studies demonstrated if malaria preceded malnutrition or vice versa.

The study also shows that the degree of parasitemia also varied among the various classes of malnourished children. Kwashiokor and marasmic-kwashiokor which are the most severe forms of malnutrition had higher density of malaria parasitemia. This may probably be explained by the lower resistance to malaria due to diminished immunity associated with severe malnutrition. Our study also suggests that more severe forms of malnutrition might likely experience severe forms of malaria as they are associated with higher degree of parasitemia. This notion is also in consonance with previous findings such as the one by Ahmad et al. which showed a positive correlation between the level of parasitemia and weight-for-age in children infected with either $P$. falciparum or P. vivax. ${ }^{20}$

\section{Conclusions}

The study clearly demonstrates that malnourished children have a higher degree of malaria parasitemia and are at a higher risk of malaria. It also shows that more severe forms of malnutrition are associated with a higher degree of malaria parasitemia.

\section{Recommendation}

The finding of this study thus recommends that all malnourished children should have access to the use of Insecticide Treated Nets (ITN), malaria chemoprophylaxis as well as recommends empiric treatment of malaria in children with malnutrition in areas where the access to malaria parasite diagnosis is not readily available. This, we opine, will go a long way in reducing mortality as well as increase the survival of children with PEM who often have malaria as co-morbidity. We also recommend that further studies on the relationship between malaria and protein energy malnutrition should be carried out by other research work.

Table 4. Malaria parasitaemia among various forms of PEM.

\begin{tabular}{|c|c|c|c|c|c|}
\hline Malaria Parasite & Kwashiokor & Marasmic-Kwashiokor & Marasmus & Underweight & Total (\%) \\
\hline None & 0 & 0 & 2 & 6 & $8(8.9)$ \\
\hline + (1-10 Parasite /100HPF) & 3 & 7 & 14 & 39 & $63(70)$ \\
\hline ++ (11-100Parasite/100HPF) & 8 & 0 & 5 & 5 & $18(20)$ \\
\hline +++ (1-10 parasites/HPF) & 0 & 1 & 0 & 0 & $1(1.1)$ \\
\hline Total & 11 & 8 & 21 & 50 & $90(100)$ \\
\hline
\end{tabular}

$\chi^{2}=35.75 \mathrm{P}=0.000$ 


\section{References}

1. Ehrhardt S, Burchard GD, Mantel C, et al. Malaria, anaemia, and malnutrition in African children-defining intervention priorities. J Infect Dis 2006;194:108-14.

2. Breman JG. The ears of the hippopotamus: manifestations, determinants, and estimates of the malaria burden. Am J Trop Med Hyg 2001;64:1-11.

3. Snow RW, Molyneux CS, Njeru EK, et al. The effects of malaria control on nutritional status in infancy. Acta Trop 1997;65:110 .

4. Murray MJ, Murray AB, Murray MB, Murray CJ. The adverse effect of iron repletion on the course of certain infections. $\mathrm{Br}$ Med J 1978;2:1113-5.

5. Hendrickse RG, Hasan AH, Olumide LO, Akinkunmi A. Malaria in early childhood. An investigation of five hundred seriously ill children in whom a "clinical" diagnosis of malaria was made on admission to the children's emergency room at University College Hospital, Ibadan. Ann Trop Med Parasitol 1971;65:1-20.

6. Murray MJ, Murray NJ, Murray AB, Murray MB. Refeedingmalaria andhyperferraemia. Lancet 1975;1:653-4.

7. Deen JL, Walraven GE, von Seidlein L. Increased risk for malaria in chronically malnourished children under 5 years of age in rural Gambia. J Trop Pediatr 2002;48:78-83.

8. Friedman JF, Kwena AM, Mirel LB, et al. Malaria and nutritional status among pre-school children: results from cross-sectional surveys in western Kenya. Am J Trop Med Hyg 2005;73:698-704.

9. Snow RW, Byass P, Shenton FC, Greenwood BM. The relationship between anthropometric measurements and measurements of iron status and susceptibility to malaria in Gambian children. Trans R Soc Trop Med Hyg 1991;85:584-9.
10. Wellcome Trust International Working Party. Classification of Infantile Malnutrition. Lancet 1970;2:302-3.

11. Oyedeji GA. Socio-economic and cultural background of hospitalized children in Ilesha. Nig J Paediatr 1985;12:111-7.

12. Cheesbroug M. Detecting and Identifying Malaria in Blood Film In: District Laboratory Practice in Tropical Countries part I. Cambridge University Press 1998;245-51.

13. Olumese PE, Sodeinde O, Ademowo OG, Walker O. Protein energy malnutrition and cerebral malaria in Nigerian children. J Trop Pediatr 1997;43:217-9.

14. ElSamani FZ, Willett WC, Ware JH. Nutritional and sociodemographic risk indicators of malaria in children under five: across-sectional study in a Sudanese rural community. J Trop Med Hyg 1987;90:69-78.

15. Mbago MCY, Namfua PP. Some determinants of nutritional status of one to four year old children in low-income urban areas of Tanzania. J Trop Pediatr 1991;38:299-306.

16. Renaudin P, Lombart JP: Anemia in infants less than 1 year old in Moundou, Chad: prevalence and etiology (in French). Med Trop (Mars) 1994;54:337-42.

17. Tshikuka J, Gray-Donald K, Scott M, Olela KN. Relationship of childhood protein-energy malnutrition and parasite infections in an urban African setting. Trop Med Int Health 1997;2:374-82.

18. Nyakeriga AM, Troye-Blomberg M, Chemtai AK, et al. Malaria and nutritional status in children living on the coast of Kenya. Am J Clin Nutr 2004;80:1604-10.

19. Williams TN, Maitland K, Phelps L, et al. Plasmodium vivax: a cause of malnutrition in young children. QJM 1997;90:751-7.

20. Ahmad SH, Moonis R, Shahab T, et al. Effect of nutritional status on total parasite count in malaria. Indian J Pediatr 1985; 52:285-8. 